\title{
Why Are Smartphones Disruptive? An Empirical Study of Smartphone Use in Real-Life Contexts
}

Maxi Heitmayer, London School of Economics and Political Science,

\begin{abstract}
Notifications are one of the core functionalities of smartphones. Previous research suggests they can be a major disruption to the professional and private lives of users. This paper presents evidence from a mixed-methods study using first-person wearable video cameras, comprising 200 hours of audio-visual first-person, and self-confrontation interview footage with 1130 unique smartphone interactions ( $\mathrm{N}=37$ users), to situate and analyse the disruptiveness of notifications in real-world contexts. We show how smartphone interactions are driven by a complex set of routines and habits users develop over time. We furthermore observe that while the duration of interactions varies, the intervals between interactions remain largely invariant across different activity and location contexts, and for being alone or in the company of others. Importantly, we find that $89 \%$ of smartphone interactions are initiated by users, not by notifications. Overall this suggests that the disruptiveness of smartphones is rooted within learned user behaviours, not devices.
\end{abstract}

\section{KEYWORDS}

Video analysis; Notifications; Smartphones; Addiction, SEBE 


\section{Introduction}

The smartphone has become a universal tool that permeates society to the degree that its overuse is starting to raise concerns. While on-screen activity is well studied, how screen use inserts itself into off-screen activity is less known. Notifications in particular have received ample attention, as they are often cited as a downside of owning a smartphone and source of distraction by users. The 'buzzing smartphone' or a 'backlog of notifications' have thus become a synonym for time pressure and stress recognized across different societies (Chiu, 2014; Hamermesh \& Jungmin, 2007). Quite naturally, notifications have also sparked the interest of researchers working on human computer interaction trying to understand the psychological outcomes for users.

Yet, current research overlooks most off-screen context of smartphone use as it relies only on the phones' sensors, if at all, and it is therefore bound to arrive at inadequate conclusions - and solutions. The relevant questions are: What was the user doing before reaching for the smartphone? What is she doing in parallel, etc.? These questions are impossible to answer with data gathered solely through the phone. To overcome this problem, we conduct an in vivo study using Subjective Evidence-Based Ethnography (SEBE) to gather first-person video of actual user behaviour in naturally occurring contexts, have in-depth interviews based on these videos with participants, and subsequently quantitatively check the interpretations arising from the data, resulting in a dataset of over 200 hours of video with 1130 unique smartphone interactions.

We discuss the limitations of current logging and field experiment methodologies for the study of smartphone use and describe the method we used to address some of them; we also illustrate this process with an analysis of how people reach for the screen. We address the questions:

- $\quad$ how users perceive smartphone notifications and how they manage them,

- $\quad$ how and in which circumstances smartphones are disrupting the everyday lives of users.

\section{Background}

About 20 years after pioneering studies in the field of notifications (Adamczyk \& Bailey, 2004; Horvitz, Koch, \& Apacible, 2004; McFarlane, 1999; Milewski, 2006) had recognized a beginning transformation in the communicative patterns of society, Fitz and colleagues proclaimed its culmination:

Notifications - visual cues, auditory signals, and haptic alerts - are the most ubiquitous feature of the most ubiquitous device on the planet. In less than a decade, receiving a notification has become one of the most commonly occurring human experiences (Fitz, Kushlev, Jagannathan, Lewis, \& Paliwal, 2019).

While most researchers and users agree that notifications are useful, many studies have shown that the pressure to be 'constantly available' (Frissen, 2000) or the fear of missing out (fomo) (Fitz et al., 2019) can affect well-being and interpersonal relationships (e.g. Höge, 2009; Sbarra, Briskin, \& Slatcher, 2019). Notifications have thus been imbued with negative connotations at the colloquial and the pop-cultural level.

At the scientific level, the discussion of notifications has been trifold: It focuses, first, on understanding the perceptions users have of why and how they use smartphones and social 
media (Baek, Cho, \& Kim, 2014; Hargittai \& Hsieh, 2010; Hargittai \& Walejko, 2008; Humphreys, 2012), how this use influences their social life (Baym \& Boyd, 2012; Boyd, 2007; Bradner, Kellogg, \& Erickson, 1999; Ishii, 2006; Schroer, 2014; Turkle, 2015), how they feel about the messages and the number of messages they receive (Lenhart, 2012; Reeves, Roy, Gorman, \& Morley, 2008; Walsh, White, \& Young, 2008), and how notifications affect their daily routines (Arnold, 2003; Bertel, 2013; Frissen, 2000; Hamermesh \& Jungmin, 2007; Roxburgh, 2004; Yeykelis, Cummings, \& Reeves, 2014, 2018). The consensus found amongst users is that smartphones have a significant impact on their daily lives, demanding large amounts of attention and regularly distracting them from their current tasks (Iqbal \& Horvitz, 2010; Kushlev, Proulx, \& Dunn, 2016). Importantly, while most users explicitly acknowledge the overall benefits of owning a smartphone, the valence towards it is often quite negative, especially when it comes to its influence on social interactions (Turkle, 2015) and to creating social pressures (Pielot, de Oliveira, Kwak, \& Oliver, 2014). Overall, the results of these studies have moved research on notifications as a driver of screen abuse and potential addiction up on the agenda

The second focus of the literature is to investigate variations in the perceived and actual 'disruptiveness' of notifications in the field, conditional on various hardware, software, and some environmental factors. Research has found that place is an important mediator of the disruptiveness of notifications (Do, Blom, \& Gatica-Perez, 2011; Exler, Braith, Schankin, \& Beigl, 2016; Oulasvirta, Tamminen, Roto, \& Kuorelahti, 2005; Yuan, Gao, \& Lindqvist, 2017). Quite logically, it seems that users are happy to be interrupted when they are waiting or idle (e.g. at bus stations or whilst queuing for food), while disruptions in places such as the cinema or the library are not acceptable (Exler et al., 2016). Moreover, when users are in "nomadic contexts", i.e. on the move or in places with a short duration of stay, they are more likely to use their phones for micro-coordination of their schedules or with other people (Do et al., 2011). Studies have further found a positive correlation between the perceived level of disruption and the amount of attention demanded by the activity users are engaged in. Notifications are thus regarded as most disruptive while users are working on, or finishing up tasks, and least disruptive when they are idle (Mehrotra, Pejovic, Vermeulen, Hendley, \& Musolesi, 2016). Research has furthermore found a negative correlation between the perceived importance of a notification and the perceived level of disruption (Beja, Lanir, \& Kuflik, 2015). This is also reflected in the finding that system messages or messages from subordinates are perceived as most disruptive, whereas messages from friends and family are considered least disruptive, particularly when users are enacting a private rather than a work-related role (Anderson, Heinisch, Ohly, David, \& Pejovic, 2019; Mehrotra et al., 2016). Moreover, the day and time when notifications are delivered (Morrison, Xiong, Higgs, Bell, \& Chalmers, 2018; Visuri et al., 2017; Westermann, Wechsung, \& Möller, 2016) and the mood users are in (Yuan et al., 2017) seem to play a relevant role for interruptibility as well, with users being more interruptible when they are in an unpleasant mood and response time to notifications being the lowest on Fridays.

Overall, while several 'intuitive' findings emerge from the literature, it is evident that the perceived disruptiveness of notifications, as well as the interruptibility of users is complex and context dependent. Further, neurological research shows that with increasing complexity, media messages quickly occupy a large portion of users' attentional resources (Cudo, Francuz, Augustynowicz, \& Stróżak, 2018). Attentional inhibition seems to be the only trait allowing users to prevent disruptive stimuli from entering their working memory, ultimately enabling them to exercise control over the disruptiveness of notifications (Tams, Thatcher, Grover, \& Pak, 2015). 
The technological solution to smartphone disruptions is for users to turn off or edit their notifications. Yet, while users ask for fine-grained notification settings, there is evidence that they do not actually use them when they are given the opportunity (Westermann, Möller, \& Wechsung, 2015), which suggests that self-regulating notification systems might be the way to address this issue. Consequently, the third and largest strand of the literature on notifications focuses on designing and testing different intelligent notification systems that ameliorate the disruptiveness and overall negative effects on attention, productivity, and well-being of users (see Mehrotra \& Musolesi, 2017 for an overview). One straightforward solution is to automatically bundle notifications to reduce the volume of disruptions, for which three batches a day seem to be the right balance between staying on top of incoming messages, not eliciting fomo, and not getting interrupted too much (Exler et al., 2017). Similarly, determining appropriate break points in between activities so that notifications don't actually interrupt the user can reduce frustration about incoming messages (Iqbal \& Bailey, 2007, 2008; Okoshi, Nozaki, et al., 2016; Okoshi, Tokuda, \& Nakazawa, 2016; Pejovic \& Musolesi, 2014; Weber et al., 2017). Another approach is to adapt notifications that users receive to the situation. While a classic study has investigated this idea by adding additional information about the call to the generic 'ring' of the phone (Milewski, 2006), recent applications have employed user preferences and machine learning to automatically detect and silence unwanted calls based on the devices' sensors and usage data (De Russis \& Monge Roffarello, 2017; Fisher \& Simmons, 2011; Oh, Jalali, \& Jain, 2015; Schulze \& Groh, 2014, 2016; Smith, Lavygina, Ma, Russo, \& Dulay, 2014; Smith, Lavygina, Russo, \& Dulay, 2014).

A third approach tries to develop systems that offer more and different types of notifications or give users entirely new ways of responding to notifications to help them cope with disruptions better. While vibrations and sounds are the easiest to perceive for users (Exler et al., 2017), the binary default choice that most devices afford (e.g. vibration or audible) seems to be appropriate for only $45 \%$ of situations; by adding visual or LED flashes, acceptance of notifications increased by 60\%(Lopez-Tovar, Charalambous, \& Dowell, 2015). It has further been shown that using external devices leveraging the peripheral vision of users results in more accurate and overall less disruptive delivery (Jones, McClelland, Thongsouksanoumane, \& Girouard, 2017; Kobayashi \& Yamada, 2013; Rasmussen, Troiano, Petersen, Simonsen, \& Hornbæk, 2016). Lastly, giving users more options to respond to notifications than simply 'opening' them (Banovic, Brant, Mankoff, \& Dey, 2014) and different gestures or other haptic interactions (Mayer, Lischke, Woźniak, \& Henze, 2018) can increase engagement with ongoing tasks and make device interactions more efficient.

Interestingly, the bulk of the literature focuses on the moment when the user takes the phone, and on that very action. Focusing on the action seems natural and is reinforced by techniques that gather data from the phone itself, resulting in device-centric research. This strikingly contrasts with the evident fact that context plays a major role in the experience and nature of "interruption". And thus, while off-screen context is difficult to record, researchers have begun to collect audio-visual data (Brown, McGregor, \& Laurier, 2013; Brown, McGregor, \& McMillan, 2014, 2015; Licoppe \& Figeac, 2013; McMillan et al., 2017; Pizza, Brown, McMillan, \& Lampinen, 2016) on smartphone usage to provide empirical evidence of what actually happens when users interact with their devices.

Many studies focusing on notifications endorse the assumption that push-based information delivery through notifications has actually superseded the traditional, user-initiated pull-based delivery. Indeed, users complain about notifications. Unfortunately, qualitative methods based purely on user-reports produce inaccurate data for tasks as minute and routinised as smartphone 
interactions. As we will show below, participant reports have sent researchers on the wrong track; it appears that most smartphone interactions are user-initiated (Banovic et al., 2014; Church, Ferreira, Banovic, \& Lyons, 2015). While users feel and think that notifications are disrupting them, and rightfully they are, in the overwhelming majority of cases it is actually the users actively checking their phones, even though they are switched to 'silent mode'. Consequently, the studies cited above testing various levels and contexts of disruptiveness produce statistically significant results based on counterfactual usage situations by forcing users to have notifications switched on. And research on intelligent notification systems, while creating innovative solutions to make notifications less disruptive, therefore misses the crucial point that the main cause for frequent device interactions, and thus the root of the experienced disruption, does not lie within the devices, but within the users.

\section{The present study}

In this paper, we propose using SEBE, a video-based, in vivo technique that combines qualitative and quantitative methods and treats participants as contributors, to study the problem of smartphone disruptions (Lahlou, 2011; Lahlou, Le Bellu, \& Boesen-Mariani, 2015). SEBE is especially valuable for explorative studies aiming to investigate actual user behaviour while it occurs, as it provides rich, contextual user data, and incorporates 'checks and balances' that avoid misremembering by participants and misinterpretation by researchers. The SEBE protocol consists of three phases: First, participants are given unobtrusive, miniature cameras worn at eye-level (subcams, see fig. 1) to gather first-person audio-visual material (subfilms). This enables participants to go about their lives naturally, without being disrupted or distracted, while gathering complete data on their daily experiences (first person perspective, wide angle, stereo sound recordings). In the second step, the Replay-Interview, participant and researcher watch the subfilms together and discuss salient moments. Here, participants can explain and reflect on what is happening in the tape, and they can object to interpretations by the researcher and suggest alternatives based on solid data as they relive their experiences. Crucially, these interviews usually unearth things that go unnoticed by participants in the course of the action, because the tapes can be rewound, slowed down, and stopped. Most importantly, reviewing one's own first-person perspective recording elicits accurate remembrance of actions, intentions, and emotions - similar to re-enactment or an access to episodic memory (Lahlou, 2011; Tulving, 2002). This grounds introspective investigation in all elements of the context of action which are made visible on the video. Finally, the researcher is left with many hours of situated first-person videos and a set of interviews that can be analysed with quantitative and qualitative techniques.

For the study of smartphone use, SEBE is particularly relevant as it allows, unlike stand-alone interviews or any form of logging method, to document the merging and the interaction of the physical and the digital environments users find themselves in, and both their online and offline behaviours in real-time. Based on the first person recordings, the Replay-Interview leverages multimodal episodic memory and offers insights into the cognitive and emotional experience of the user behind the behaviour itself (Glăveanu \& Lahlou, 2012; Lahlou, 2011, 2018; Lahlou et al., 2015). 


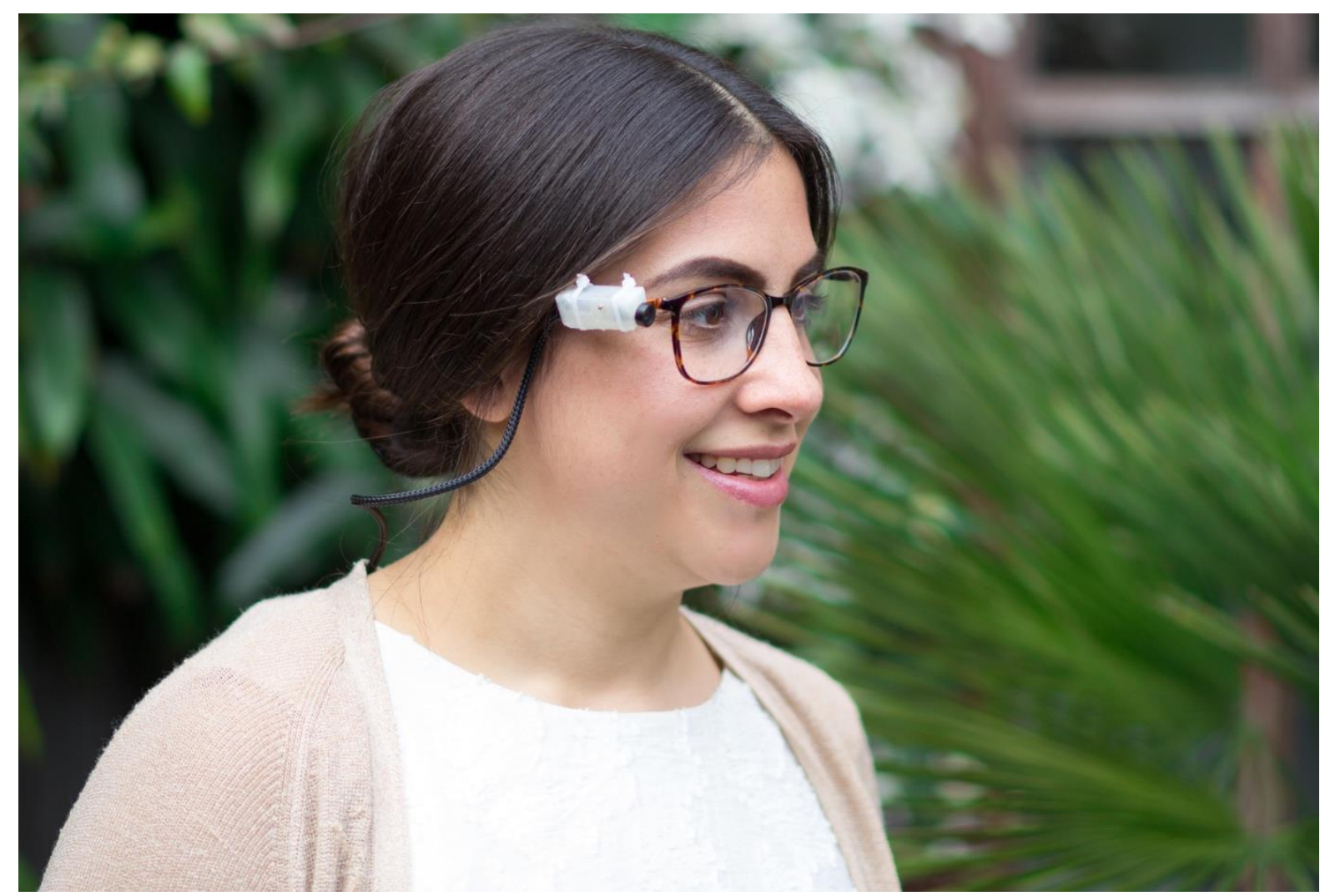

Figure 1. A researcher wearing the Subcam. The camera weighs only 7 grams and can be mounted on a pair of research glasses or the participant's own (here); it has about 3 hours of autonomy with the internal, and several days with an external battery.

\section{Data Collection}

The SEBE protocol includes stringent ethical guidelines ensuring participants' full control over the data throughout the research process (Everri, Heitmayer, Yamin-Slotkus, \& Lahlou, 2020); the protocol received ethical approval from the London School of Economics and Political Science (08.11.2017). Participants have been asked to wear their subcams throughout the day, engaging in everyday activities as they would normally, to capture smartphone use in different settings. Participants have been asked to wear their subcam on at least three consecutive days, collecting at least 5 hours of video material. Data collection took place in the UK, France, and Germany with the majority of participants residing in the Greater London area. This generated an international but predominantly European sample of $\mathrm{N}=37$ participants. The age of participants ranged from 21 to 29 years with $43 \%$ being female. Participants have furthermore been instructed to only wear the camera in situations in which they felt comfortable and could forget about wearing it. Allowing participants to self-select when to wear the subcam results in more natural behaviours, while also protecting their privacy. As part of the protocol, participants are regularly reminded they can delete data if they feel they have recorded something undesired. No participant used this opportunity. This has generated a data corpus spanning a breadth of activities and locations like commuting, working in the office, attending lectures at university, spending time with friends and family, and relaxing at home. Throughout the sample we find a rather even spread of subfilms recorded at home, work, and outside. Overall, the data corpus comprises over 200 hours of video material.

\section{Findings}

We first present a qualitative analysis based on the Replay-Interviews where participants comment on their actions, intentions, and emotions as they review their own recordings. This 
phase informed the systematic coding of interactions with the smartphone, which is then analysed in the quantitative analysis that follows.

\subsection{Qualitative analysis}

The Replay-Interviews have been video-recorded, transcribed literally and analysed using directed Qualitative Content Analysis (QCA) to describe emerging themes and ideas in a systematic and coherent way (Mayring, 2000, 2015; Schreier, 2014). All participants judged that the subfilm material they had gathered constituted an accurate and representative depiction of their behaviour, with many of them reporting that after wearing the camera for a short time, they were not conscious of it anymore ("Did you see that? I wouldn't have thrown around the plastic bottle like this if I was thinking about the cam"; P5). However, while the camera weights 7 grams and is easily forgotten, some participants who do not wear glasses reported that they were conscious about the device at times ("The embodied way of the glasses is hard to miss"; P4). This did not, according to them, change their behaviour.

Participants turned out to be enthusiastic about the SEBE-technique. When prompted in the Replay-Interviews, they reported that they enjoyed being able to re-live their experiences, and that they observed behaviours they had not been aware of before. Several participants subsequently recruited other participants for the study. The interviews covered a broad range of smartphone activities in which users engaged on tape. The qualitative analysis of this rich and diverse material yielded six major themes with two to four subthemes, respectively. Within the limited scope of this paper, we focus on the three most pertinent to the experience of disruption, that is, why participants pick up their phones, their preferences for and responses to receiving notifications, and the usage habits and strategies they have developed.

\section{Picking up the phone}

First, when asked about why they picked up their phones, participants usually reported it feeling natural or automatic, and even unconscious "like when you cough and put your hand over your mouth" (P24). Moreover, participants often exhibited genuine surprise at the intensity of their use:

I wouldn't consider myself someone who isn't attached to their phone much. But seeing this has made me realise that I don't even remember picking it up-I think I use it a lot more than I let myself believe. It's really interesting for me to see how much I use it and how much I rely on it. (P27)

In another striking example one participant spent about an hour cooking dinner and then turned to her phone as soon as she had plated the food. After fifteen minutes of the food getting cold and not having eaten, she exclaimed in the Replay-Interview: "I just don't get it, even though I'm so hungry I'm still on my phone" (P1). Participants also reported how frustration or boredom with the ongoing activity led their minds to 'drift off', and to eventually pick up the phone or switch to their social media. This commonly applies to unenjoyable work tasks but also to other activities that were perceived as non-rewarding, like cooking, cleaning, or commuting. 

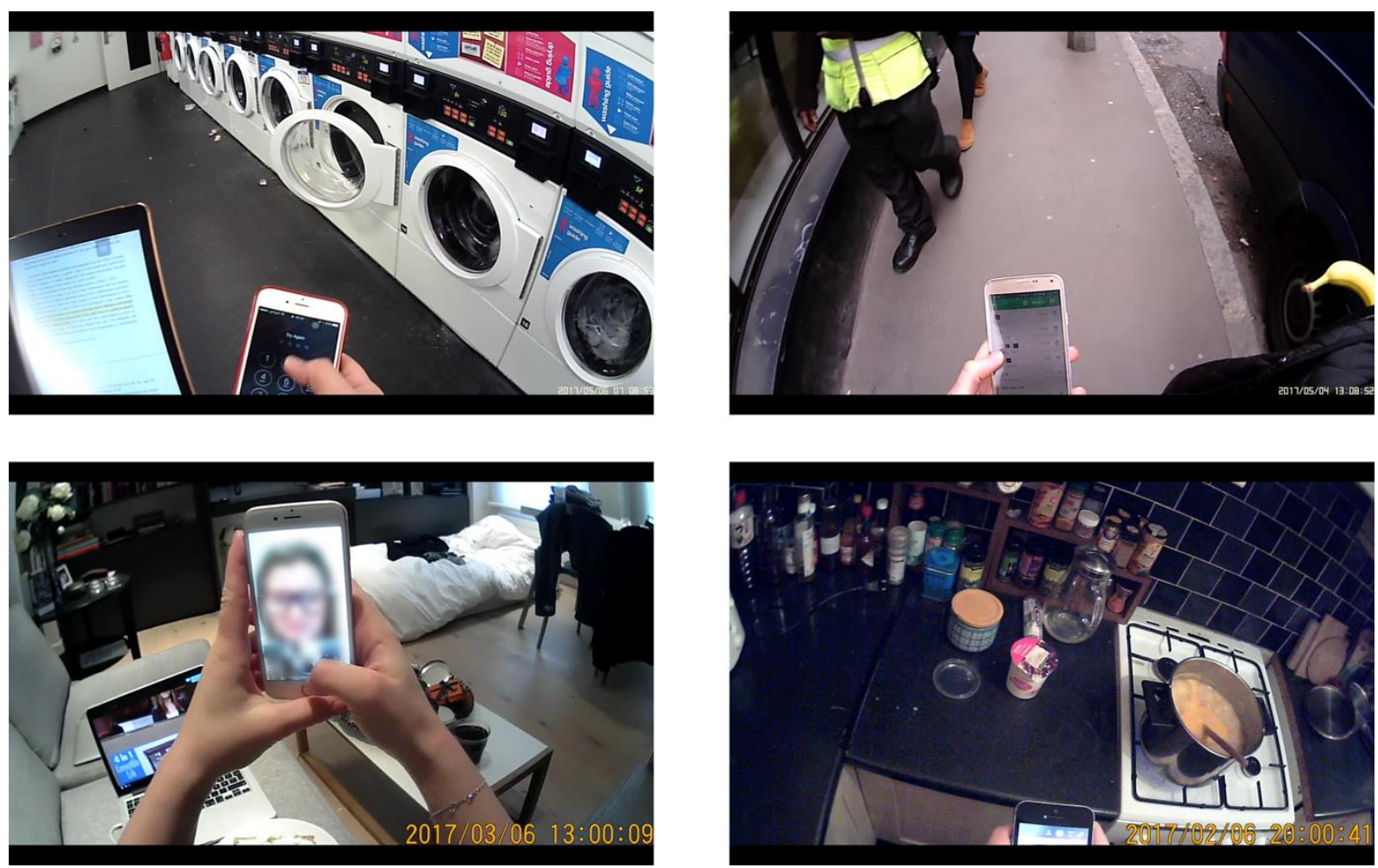

Figure 2. Various instances of smartphone use (clockwise) extracted from subcam recordings: Tablet and Smartphone while doing laundry, looking up public transport on the go, watching videos and sending selfies during dinner, looking up recipe while cooking.

Second, engagement with one social media platform usually triggered a chain of subsequent engagements with other platforms, characterised as getting caught in a loop, which lead many participants to spend more time on the phone than they wanted as social media suggests new options to them: "And I tell myself those lies. You know, like 'I'm gonna finish this video and then I'm going back to work'. But then I keep scrolling like 'No, just one more video' (P3). On one hand, this can be attributed to a 'lingering' loop pattern that entails participants cycling through apps, and different functions (e.g. Instagram feed and Instagram stories) after finishing an activity on the phone, even though there are evidently no new notifications.

It happens often when I've just been on my phone. I wasn't just using it to procrastinate, I was actually using it to do something that was useful. But then, it's just something that there's like feedback loop, you know, and you have to... (P12)

On the other hand, most participants had routine orders in which they accessed their social media apps. In combination with automatic pick-ups, this induces participants to go about their routines while they figure out why they picked up their phones in the first place:

Here I actually check the time and then go about my routine. So, WhatsApp, Email, the important things, and then faffing. Probably wanted to check the weather or something like this and I usually go on Instagram or Facebook. I pick it up for something, then I forget what I wanted to do and check all the things, my routine, and then I remember, ah yeah, I wanted to check the weather. (P19)

A third, striking finding is that almost all participants pick up the phone, unlock, play around with them and put them back without doing anything in particular ('fidgeting'). This 
often also includes opening and closing apps without an evident purpose and even typing. Fidgeting is user-initiated and happens without any prompt from the smartphone. Most participants could not give a reason for their behaviour beyond stating that it felt natural to regularly check the phone. A few participants also reported that fidgeting with apps on the touchscreen felt relaxing or therapeutic.

Overall, picking up the phone seems to be widely automatic and habitualised, with participants often ending up with their phone in hand without intending to do so, or longer than they had originally intended. In this context, all but two of our participants mentioned that they felt they spent too much time on their phones.

\section{Notifications}

When talking about notifications, participants often mentioned the social pressure of constantly being available as having a negative impact on their well-being. Apart from it being "mentally tiring" (P19), participants specifically highlighted others getting mad at them for not responding promptly:

\section{Realistically how long is it going to take you? I'm never in a situation where I just can't answer my phone you know? There's this expectation that you're going to be on your phone. People literally say to me: 'Why didn't you text me back because I know you had your phone on you?'. And I just say: 'Yeah, you're right, I probably could have to be honest. I just chose not to for once, you know.' (P21)}

As a qualification to this, though, most participants did describe different levels of perceived urgency to respond, depending on the nature of the message and who sent it. Notifications connected to managing schedules and offline activities emerged as the highest priority.

Things that require immediate responses are, I don't know. It's 12:45, I have a lunch date for Ipm and I get a notification: 'I need ten more minutes'. Then I'd write: 'Yeah sure, no problem' (P25).

Similarly, Emails and other work-related notifications were, generally regarded as high priority, not only demanding a quick response, but also turning other notifications into distractions and nuisance. In contrast, even though participants generally agreed that group chats were a source of distress and most messages in them rather unimportant, longer absence from a conversation was cited as a reason to respond: "So, it's because there have been a few messages and I have been silent for a while" (P4). Linking this to the previously discussed pressure of being available, while there seem to be notifications that are more urgent in nature than others, social pressure appears to drive perceived urgency of notifications as well.

Most importantly, all participants characterised notifications as disruptions. In the subfilm material, receiving a notification nearly always led the participants to immediately interrupt their current activities and attend to their phones. In our discussions, participants took an almost fatalistic view on interactions with their smartphones:

Usually I just have my phone on the table and I won't look at it. Hopefully nobody messages me but if they do then I will. (P26) 
I try and put it a bit away but obviously if a message pops up then I want to answer right away. Not that I always do but I want to. (P36)

I just feel like anytime someone messages me it just sets off a stream of 'oh I can do this, this and that' you know? It's not ideal, which is why I'll let my phone die or put it in a different room because I feel like once you pick your phone up you've got one notification then you have ten of them. (P21)

In sum, participants appear to be caught in a double bind where having the phone in a place or setting that makes notifications noticeable to the sense renders it impossible not to engage with them immediately, and when notifications are not noticeable social pressure and a backlog of things to deal with accumulate. As one participant poignantly put:

A lot of the apps that I have on there, I've switched off the notifications. Which means that I'm not hassled as much. But I find myself checking more regularly to see whether something's come up. (P29)

\section{Usage habits \& strategies}

To manage the intellectual tension between the different demands and desires around engaging or disengaging with the phone, participants have developed a nuanced mixture of intentional strategies and unintentional habits that have developed over time.

All participants cited avoidance strategies that helped them to not attend to their phone. These can be broadly categorised as either 'software' and 'hardware' approaches. Software strategies focused on adjusting the phone's settings to specific situations. Usually, this entailed having multiple sets of notification settings for specific contexts. Most participants differentiated between work-settings, in which the phone should not make lights or noises, and leisure settings, in which it could. The exact settings varied greatly between participants with all three common forms of notifications (tactile, visual, audible) being described as either the least or the most disruptive by some. A more drastic approach entailed handing over the password to social media accounts to a friend to control the access.

Hardware strategies were aimed to alter the physical connection participants had with their phones. These include moderate approaches such as turning the phone upside down or putting it out of immediate reach, but also harsher measures such as switching off the phone, hiding it under a pillow, wearing earplugs to not hear the phone, and even leaving it at home when going to work or university. Most of these strategies, again, exhibited a fatalistic view on smartphone interactions and ultimately sought to address a perceived lack of self-control on the side of the participants. As one of them described:

I use my phone a lot yeah, but I try to plan in advance to avoid hurdles. If I just go ahead with my day it's difficult to control myself but if I plan in advance then; you silence the chats or a particular one. (P19)

Moreover, social aspects were described as drivers of avoidance strategies, both for work and leisure contexts. At work, participants said that they wanted to appear focused and hardworking, and that it "would be embarrassing when the phone went off in a meeting, etc." (P6). Especially with regard to newspapers and other non-social media apps, some participants mentioned that they want to receive the information contained in the notifications, but that they did not need it immediately. For leisure contexts, most participants described people who used 

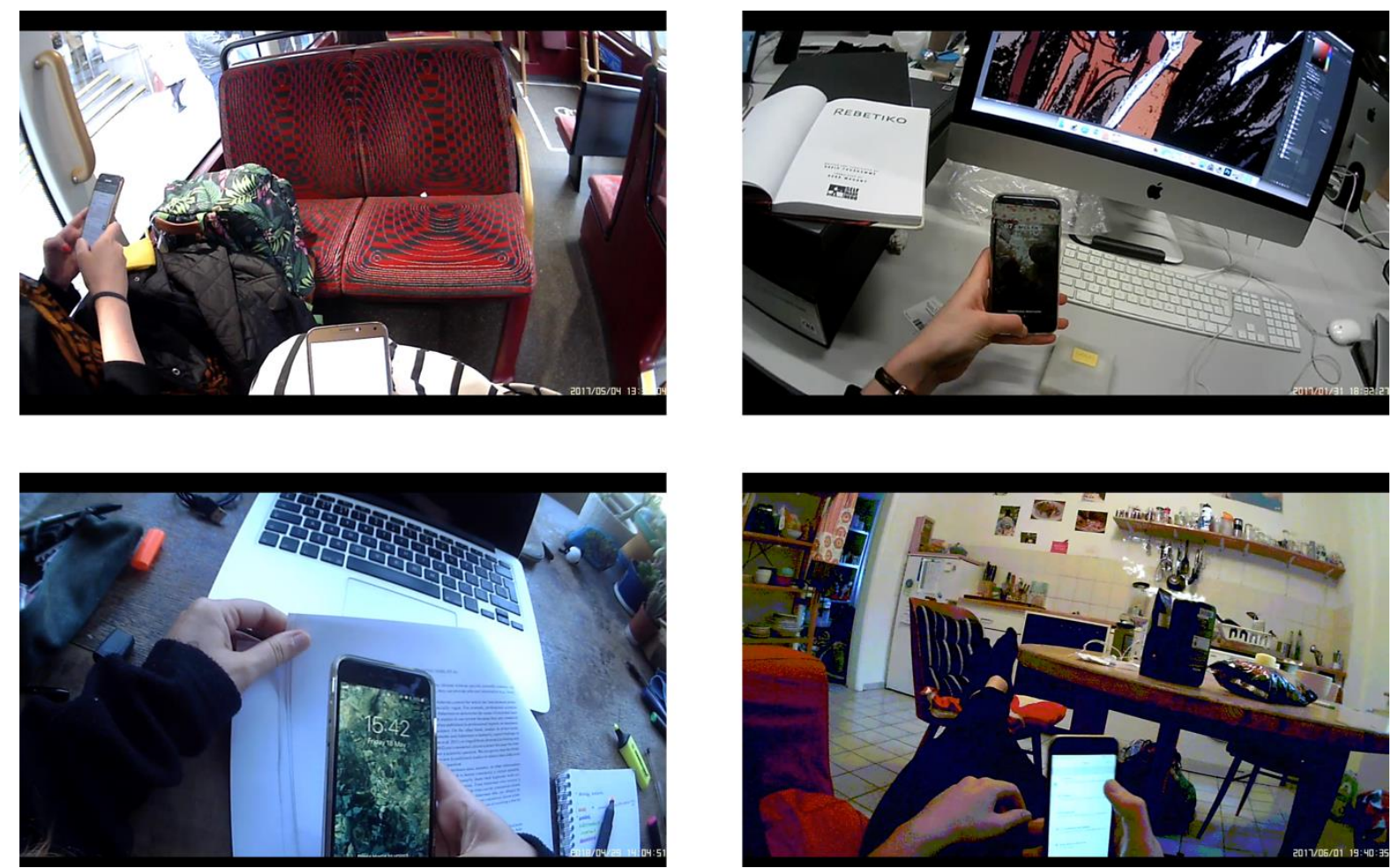

Figure 3. Various routines of smartphone use (clockwise): Smartphones during commute, answering messages during 'mental break', lock screen check after turning the page, 'Coming home' with groceries still on the table.

their smartphones during social occasions as annoying and conversations in which people were on their phones as 'slightly lacking', since people got absorbed in their smartphones: "I would say that when I see something that actually matters online and I need to concentrate, some of my responses are... just fillers" (P27). Hence, several participants also saw this as an opportunity for impression management or to set a positive example: "It's like, the way I want to be seen by others and I want to control that, I don't want to be seen in a different way. I want to be this guy who pays attention" (P18).

On the other hand, participants also reported engagement strategies that enabled them to interact with their phones when they wanted and, at times, while carrying out other tasks. Reflecting the dilemma of having to check the phone and wanting to focus on other things, most participants exploited natural breakpoints between activities and actively created short mental breaks in order to 'engage to not engage'. Participants thus used the phone when they knew their computers were loading for some time, while they were waiting for water for a tea to boil or when they were walking from one place to another. Participants also used their phones to fill gaps in between activities: "There's no notifications on my phone. I'm just going on it because I'm awkwardly standing in line" (P27).

Several participants furthermore described that they check all apps and notifications and reply to all unanswered messages in preparation of putting the phone aside for another task: "I try to get rid of the messages before I work, so I can focus. Otherwise, it is in the back of my mind" (P7). At the same time, particularly when their current task was either very stressful or dull, participants allowed themselves to check the phone to give their minds a little break, and as an excuse to take time off working. Finally, several participants stated that they sometimes leave the phone face up on the table when they want to be distracted, to 'take their mind off things', or 'slowly fade out work in the evening': 
It's something to look forward to when I open Instagram or Facebook. When I have my phone in my hand I know that I have access to that now. I feel like I'm obliged to look through some kind of social media. I don't know how it is for other people, but it is something that I've ingrained in myself. (P24)

We also found specific routines that pertained to going to bed or waking up. In this context, smartphones and social media were described as a tool that helped participants to wake up ("a light that wakes up your eyes"; P17) and to fall asleep. At the same time, participants also switched off the phone or even left it in another room for the night to prevent themselves from going on it ("Otherwise, I'm always reaching over when I can't sleep or whatever"; P37).

A particularly interesting finding was that one participant would go to the bathroom if he had to respond to a message while in company:

It's going to sound weird but what I do is, I go to the bathroom. Because that's socially acceptable. Sometimes I also use it but often I just go there and reply to messages for 5 minutes. I'm not rude in front of people as I'm using the toilet, but I'm not. (P18)

Once more, this highlights the dilemma of social expectations around smartphone use. On one hand, the physically present people expect him to not use his phone, on the other, those who are not expect him to check his notifications.

At the end of the interviews we asked participants whether they had noticed anything in their behaviour they weren't aware of before if this had not arisen naturally from the conversation already. Generally, the answers to this question were mixed, with some participants stating they thought they use the phone less than what appeared on recording (usually paired with negative valence), and some saying they saw what they expected (usually with neutral valence). The majority of participants, however, were surprised at the frequency with which they checked the phone, and the automaticity with which this occurred:

It's just this automatic thing. I don't remember getting my phone out. When I see that moment, I don't remember doing that [...] I feel as if to feel normal I have to have my phone next to me and I'm surprised that I keep checking it. (P28)

As a methodological side note, this lack of awareness by the users of their own automatic behaviour illustrates and emphasizes our caveats in the introduction about excessive reliance on user reports to understand the use of smartphones. While we expected some differences between behaviour and awareness, we (and our participants) were struck by their amplitude. The quantitative section that follows will illustrate this further.

\subsection{Quantitative Analysis}

After analysing the interviews, the subfilms were coded quantitatively. Every time participants used their smartphones on tape, we recorded duration, time elapsed since last phone interaction, location, type of interaction, the context they were in (e.g. working at the office, commuting), whether there was a notification (and if so, what type) and the nature of the activity. When users switched between apps or functionalities within one continuous session of using the phone, we coded this as multiple interactions. ${ }^{1}$ Overall, this resulted in a dataset of $\mathrm{N}=1,130$

\footnotetext{
${ }^{1}$ Unfortunately, the subfilms for three participants were corrupted in the transfer process after the interview, resulting in an $\mathrm{N}=34$ for the quantitative analyses.
} 


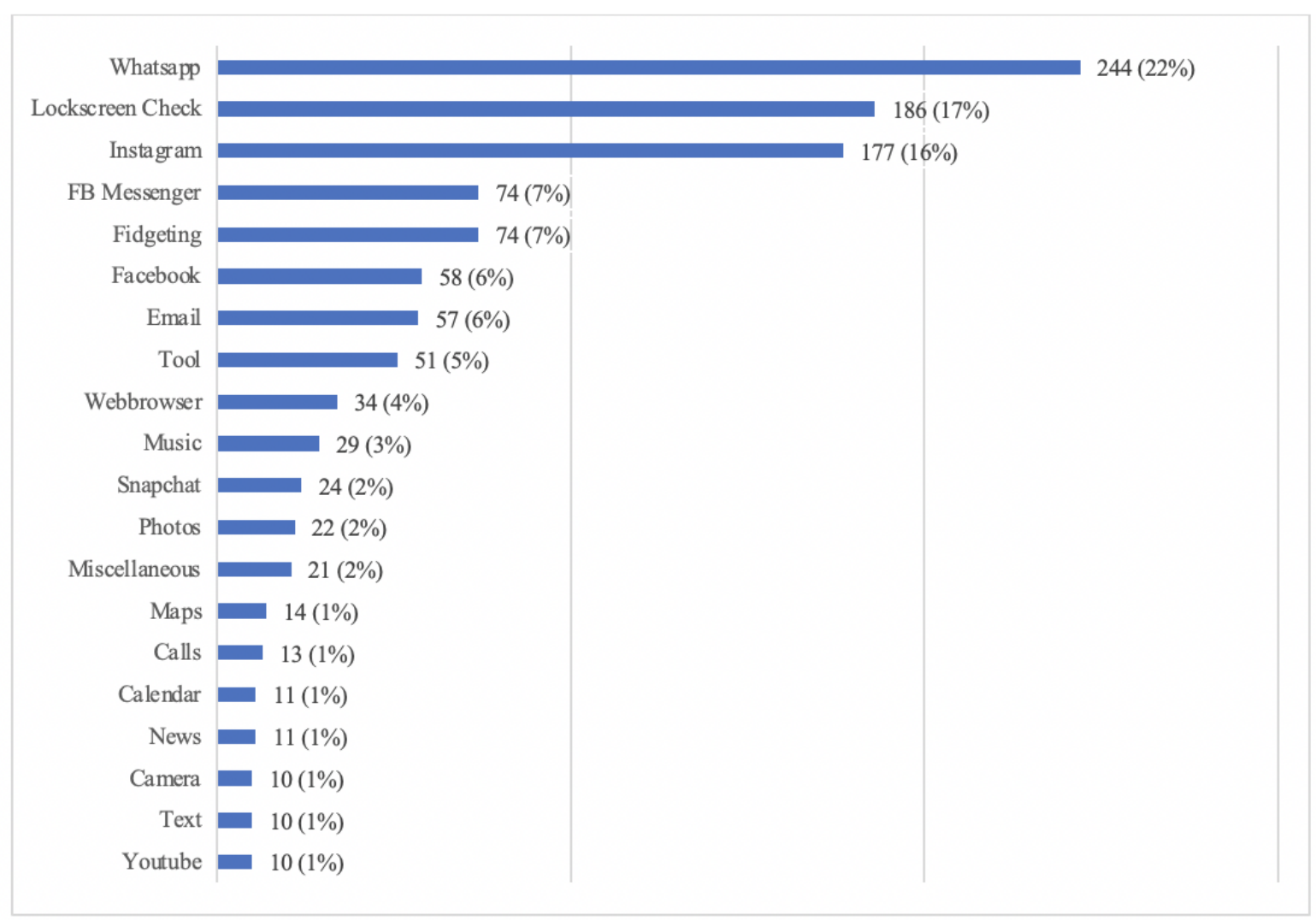

Figure 4. Observed smartphone activity categories by frequency (Activities with a frequency <1\% have been excluded).

smartphone interactions. We did not find any significant differences in use for sex, age, or education.

Smartphone interactions lasted $64.4 \mathrm{~s}$ on average. Note that this value is affected by several substantially longer phone sessions caught on tape; $25 \%$ of interactions lasted $8 \mathrm{~s}$, and $50 \% 23 \mathrm{~s}$ or less. The same picture emerged for the time elapsed between smartphone interactions, which averaged at $290.5 \mathrm{~s}$, with $25 \%$ of intervals between use being $40 \mathrm{~s}$, and $50 \%$ being $137 \mathrm{~s}$ or less. Using these averages, our findings purport that participants engage with their phones for 10 minutes every hour in a 'one minute every five minutes' pattern. The most frequent smartphone activity we observed in our sample was using WhatsApp, a popular messaging app in most of Europe, followed by the lock screen check, i.e., briefly activating the phone screen without unlocking all of the phone's functionalities, and Instagram. Phone calls, text messages, and maps only made up about $1 \%$ each of the total sample (see fig. 4 ).

We then ran several ANOVAs to investigate some of the issues that emerged from the interviews. We find that smartphone interactions last longer when users were interacting with their phones before, compared to when they come from a non-smartphone activity (104s vs. 46s; $(\beta=58.71, \mathrm{SD}=9.36, \mathrm{p}<0.000)$. This confirms the idea that users can get caught in a loop when they engage with their smartphones for longer sessions that include multiple apps. Furthermore, while the type of activity participants were engaged in did not significantly influence time between pickups, its influence on the duration of the smartphone interaction was highly significant. For example, interactions with Facebook $(\beta=113.74, \mathrm{SD}=19.73, \mathrm{p}<0.000)$, Instagram $(\beta=63.11, \mathrm{SD}=12.01, \mathrm{p}<0.000)$ as well as the phone's web browser $(\beta=199.15$, $\mathrm{SD}=25.17, \mathrm{p}<0.000)$ lasted significantly longer than others activities. These apps are prime examples for the endless scrolling and getting caught in the loop described by participants. Note that while the ANOVA is relatively robust, due to the nature of user behaviour the data 

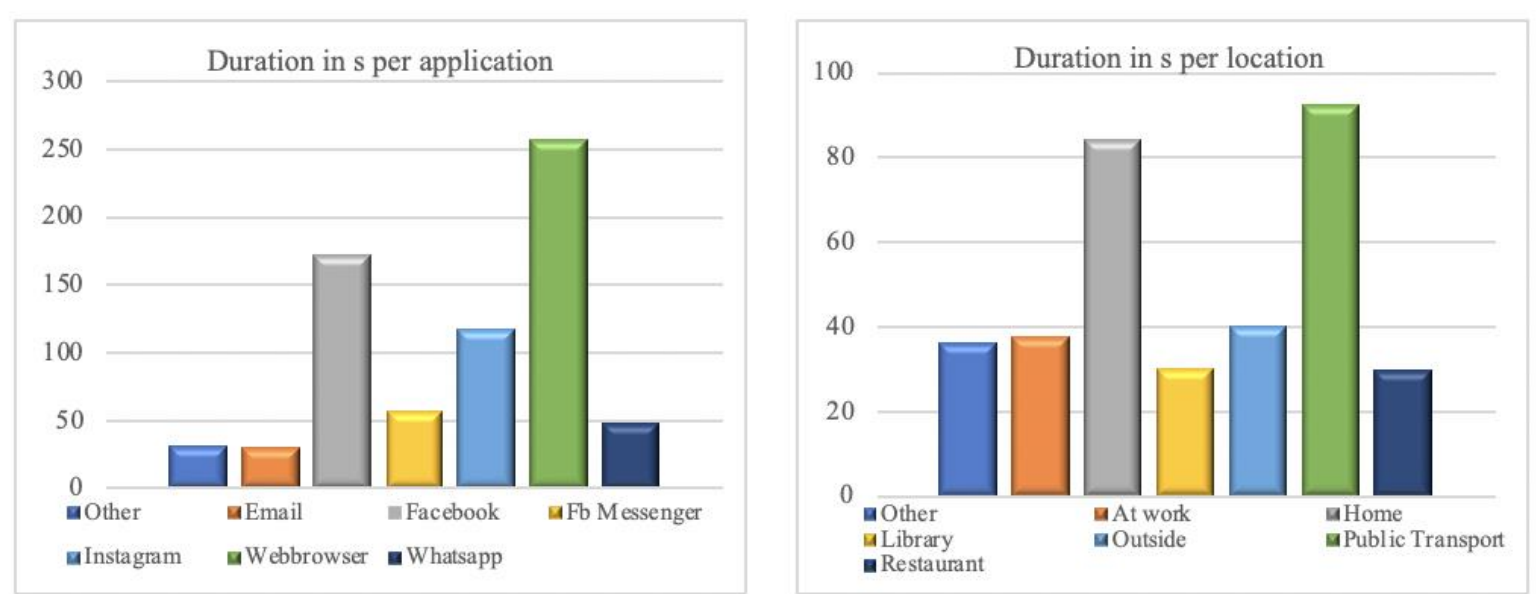

Figure 5. Mean duration of smartphone interaction in s per application and location.

is skewed and the Bartlett's/ Brown-Forsythe tests were significant, which warrants further investigation of this finding with a larger dataset.

Our results also indicate that phone interactions last longer when users are alone as compared to being in company $(\beta=22.46, \mathrm{SD}=8.84, \mathrm{p}=0.0112)$. Interestingly, the effect on time elapsed since last pick up is only marginally significant $(\beta=-58.68, \mathrm{SD}=29.94, \mathrm{p}=0.05)$. This suggests that the overall notion that being on the phone is considered rude or undesirable when one is in company leads participants to spend less time on the phone, yet they still seem to feel the need to regularly check it. Moreover, we find that the location users are in significantly influences the duration of smartphone interactions $(F(10,1118)=3.2, p<0.000$, see fig. 5), but not the time elapsed between interactions $(\mathrm{F}(10,616)=1.46, \mathrm{p}=0.151)$. Unsurprisingly, testing specifically for home and work, we find that phone interactions last longer when users are at home $(\beta=42.53, \mathrm{SD}=8.77, \mathrm{p}<0.000)$ and shorter when they are at work $(\beta=-36.02, \mathrm{SD}=10.29$, $\mathrm{p}=0.005)$, but even in these specific comparisons, we did not find a significant effect for time elapsed between interactions ( $\mathrm{p}=0.189$ and 0.065 respectively).We further controlled for instances in which participants worked from home; they spent less time on their phones, as compared to other activity contexts at home $(\beta=-59.05, \mathrm{SD}=16.94, \mathrm{p}=001)$, which suggests that the activity seems to matter more than the activity context. Overall, this again suggests that, while participants seem to engage in longer phone sessions in the comfort of their home and shorter sessions while at work, the intervals in which they check the phone are not affected by their location.

Most importantly, however, we observed that participants had their phones on silent mode or located out of noticeable distance in the vast majority of cases as $89 \%$ of interactions were user-initiated. Of the $11 \%$ of the interactions that were initiated by a notification, $59 \%$ were visual only, as compared to sound, vibration or a combination of these. In contrast, every sixth smartphone interaction in our sample was a lock screen check. These lasted $5.2 \mathrm{~s}$ on average and entailed either returning to the previous activity or fidgeting with the phone briefly when no new notifications were available, or reading or skimming through notifications in case there were any. Again, only $15.6 \%$ of these brief checks were initiated through notifications, with $63 \%$ of them being visual only. This evidence corroborates participants' statements about regularly checking the phone out of habit, rather than being triggered by external stimuli.

We then controlled for differences between participants and the effect of differentiating between single interactions and sessions. Looking at individual participants we observe 


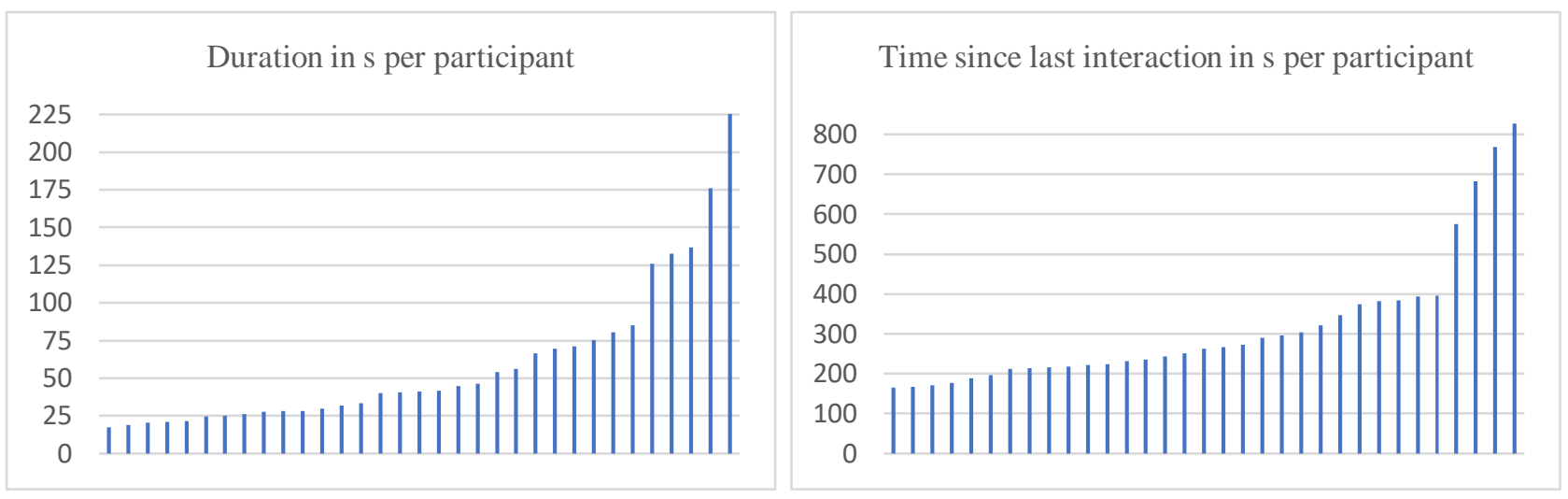

Figure 6. Mean duration of smartphone interaction and mean time since last smartphone interaction in $s$ per participant.

relatively homogenous usage patterns in our sample that lead us to believe the general findings adequately depict individual experiences (see fig. 6). For duration of interaction, roughly half of participants ranged between 20 and 30s, the other half between 40 and $85 \mathrm{~s}$ with five outlier cases over 120s on the high end. While it is difficult to directly compare individual cases because of the unique composition of situations participants have recorded, one initial pointer for the source of these differences may be that the participants with significantly higher average durations recorded much more interactions that took place in public transport or at home (between $83 \%$ and $100 \%$ compared to $54 \%$ on average in the sample) than the rest of the sample, which we have found to be locations that are conducive to longer use. For time since last interaction a similar picture emerges with half of the individual means ranging between $165 \mathrm{~s}$ and $250 \mathrm{~s}$, and the other half between 250s and 400s with four outliers at the high end again. Just as in our previous analyses, we did not observe any systematic variation from other participants in activities participants engaged in or locations they were in that can explain these outliers. It appears, again, that intervals between smartphone interactions depend on habits and internal motivations, not external influences.

Lastly, we controlled for the effect of treating full smartphone sessions that consisted of multiple interactions (e.g. different apps), as one unit of analysis, finding that the results remain the same. Out of 774 sessions, the majority consists of just 1 interaction (78\%), with about $12 \%$ of sessions comprising of 2 interactions, $6 \%$ of 3 , and only $4 \%$ of 4 or more interactions. The frequency distribution for the number of activities per session remains the same regardless whether the interaction was initiated by a notification or the users, again emphasizing the importance of routinised behavioural patterns and an acquired 'drive for the screen' for smartphone interactions.

The mean duration of sessions is unsurprisingly longer than that of individual interactions $(94 \mathrm{~s}$ vs 64s). Interestingly however, the mean duration for sessions and for single interactions is almost exactly the same when notifications arrive, and significantly shorter than either of the overall means (43s). Finally, just like individual interactions, about $11 \%$ of the full sessions were initiated by notifications, the rest by users (see fig. 7). 


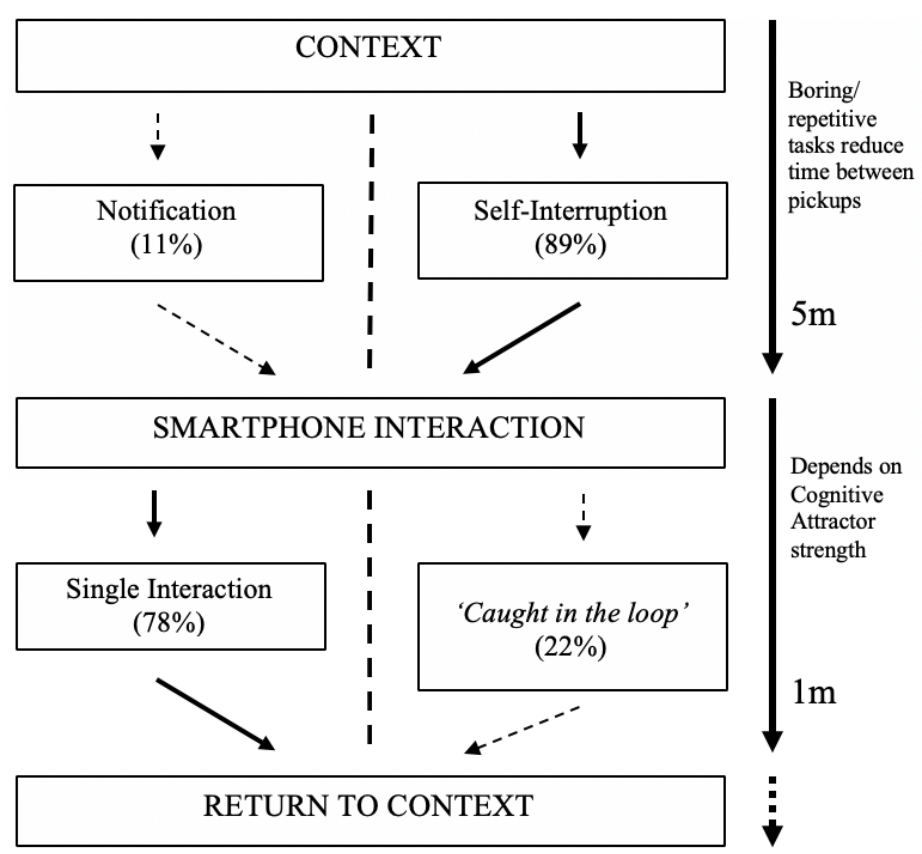

Figure 7.Process diagram for smartphone interactions.

\section{Discussion}

Smartphones afford a large variety of activities to their users in numerous contexts. Through the use of SEBE, we have been able to gain some unique insights into our participants' daily lives with their smartphones, and their subjective user experiences. We have furthermore been able to triangulate our findings, verifying researcher interpretations against participant comments, and participant comments against empirical observations.

Notifications, while being seen as important for managing urgent work and 'life admin' tasks, mostly emerge as disruptions and sources of social pressure, both when they are noticed by the senses and when participants actively check their phones for updates. It appeared almost impossible for participants to not immediately interrupt their current activities and attend to their phones when they noticed a new notification with their senses. They therefore often switched off notifications or limited access to the phone. In these situations, however, participants reported the social pressure of being available and the worry of missing something important as becoming increasingly more pressing as time elapsed, ultimately leading them to check their phones ("I think we're constantly conscious of thinking that someone might have sent a message"; P29). Most participants consequently appear to have adopted the fatalistic view that their phone disrupting the flow of other activities one way or another just cannot be avoided.

Our quantitative findings show that participants prefer to restrict the access to their phones or mute them: We find that only about $11 \%$ of smartphone interactions in our sample were triggered by participants actually perceiving a notification with their senses. Thus, in the large majority of cases it is users pulling information from the phone rather than smartphones pushing it onto them, which is in line with previous findings (Banovic et al., 2014; Visuri et al., 2017). Hence, our quantitative analysis suggests that participants have acquired a habit of reaching for the screen about every five minutes. 
The qualitative data gives three accounts for this: One, participants use their smartphones to structure their schedule and interweave other activities with short smartphone breaks. Two, participants are subject to social and professional pressure to check for potential new information. Three, using the phone as a 'one-stop shop', both for staying on top of things and for escapism seems to direct automatic and unconscious fidgeting behaviours towards the phone rather than other devices or objects. These behavioural patterns have become deeply internalised, automatic, and mutually reinforcing; it will require substantial behavioural change for participants if they wish to engage with their smartphones less, and particularly less frequently.

Taken together, these findings show that research trying to manipulate hardware factors to make notifications less disruptive is not aiming at the right target. Specifically, it overlooks that while users report that they consider notifications disruptive - and the ones they do receive are disruptive indeed - they have found their own coping mechanisms which usually entail silencing the phone and regularly checking for notifications, which makes up the majority of smartphone interactions. Yet, even with their devices silenced, users felt that their phones were disrupting them; it is, thus, evident that the problem is not caused by external disruptions by the device such as sounds or vibrations, but by habitual, internal self-disruptions. Interestingly, as we saw, users are dissatisfied with realizing how frequently and unintentionally these selfdisruptions occur and often attribute this behaviour to the mere presence of the phone:

I didn't think I checked the phone then but I do have it out. I think it's an automatic... like when you have a cough and you put your hand to your mouth - it's something like that. When I see that moment, I don't remember getting my phone out. [...] I feel as if to feel normal I have to have my phone next to me and I'm surprised that I keep checking and I'm just surprised by the amount of time I'm spending on my phone. This has been helpful to me because a lot of times I don't realise how much I'm checking my phone and it makes me question it. (P24)

Another understanding of the disruptiveness of smartphones participants highlighted is getting caught in the loop. Many users seem to find it difficult to only use their phones briefly, and to only do what they originally intended to do with it. Moreover, certain apps that feature a 'feed' that allows for continuous scrolling through information (or similar features) were described as especially attention-grabbing, often leading users to spend much more time on their phone than they originally intended.

In line with the qualitative findings, the quantitative analysis revealed that duration of smartphone use was shorter when participants received notifications compared to when they self-disrupt. Thus, smartphone use appears to be more purpose-driven when users receive notifications, and more distraction-seeking when it is self-initiated. User interactions also lasted longer when participants had their phones in hand already, suggesting that going beyond a single, brief smartphone interaction tends to trigger longer phone sessions. In line with this, we find that use of apps that allow scrolling through a newsfeed or watching stories (particularly Instagram and Facebook, but also the web browser) was indeed longer on average than other phone activities. This suggests that users are correct in assuming they are running the risk of getting caught in the loop when they engage with their device: they get trapped in a "cognitive attractor" (Lahlou, 2007) that provides (small) amounts of satisfaction at a low cost with a high salience of the stimulus . 
More generally, we find that interactions lasted 64.4s with 290.5s intervals between them on average, giving a 'rhythm of smartphone interaction' of roughly one minute every five minutes (see fig. 7). These numbers reproduce the findings of Yan and colleagues (Yan, Chu, Ganesan, Kansal, \& Liu, 2012), but are much lower than what two other studies have found (Van Berkel et al., 2016; Visuri et al., 2017). As suggested in the literature, we also find that location and context influence how much users interact with their phones. Crucially, however, while participants usually reported being more on their phone when they were in leisure and less when they were in work settings, the quantitative analysis reveals that it is only the duration of smartphone interactions that is shorter when participants are working, while the intervals between interactions remain unchanged. The same picture emerges for being in company, which again only results in a reduction in duration of interactions, not a change in frequency. This suggests that participants were sincere when they expressed that they find it rude to be on the phone when other people are around, and that they do try to be on their phone less when they want to be productive, but it is also clear that participants underestimate just how routinised, habitualised and 'automatic' frequent smartphone interactions have become in the flow of their daily activities.

Overall, there seems to be evidence for the case of smartphone interactions being userdriven now, which is yet to be integrated into the wider research agenda of the field. The disruptiveness of smartphones is not of a physical or sensory nature, but rather lies within the demands they place on users' minds, and the interactive potential they offer. While notifications are disruptive indeed when they occur, the vast majority of smartphone interactions stem from automatic and habitual self-disruptions, which means that we need to approach the problem differently. Of course, making those notifications users do receive with their senses less disruptive is certainly a step into making their user experiences and their daily lives better. But in the overwhelming majority of instances when smartphones interrupt or disrupt users, it's not actually the devices, but the users themselves.

For research to better inform design practice in the future, we therefore propose that the disruptiveness of smartphones should not be conceptualised as a question of design, but one of embodied competences, i.e., user routines and practices. Research should focus on better understanding the habits and routines users have developed with their smartphones to help users better align their behaviour with their intentions. For this, we argue, it is essential to use first-person, in vivo techniques like SEBE to avoid jumping to 'intuitive' conclusions too quickly. Specifically, we see four avenues for further investigation:

A first potential avenue should further explore the motivations and goals of users when they pick up their phones. While there is some quantitative evidence on individual differences in smartphone use, video-ethnographic methods are a highly promising route to understand the different engagement and avoidance strategies that emerge naturally as our analysis has revealed. Especially examining the personal, but also the contextual factors that are antecedent to wanting to be disrupted and wanting to be disrupted will be relevant to understand different user profiles and their specific needs and problems. In this process, figuring out best practices together with users will be highly informative to generate effective and lasting interventions that can help users align their behaviours with their intentions. SEBE should furthermore be combined with experimental approaches to explore and empirically validate the smartphone interaction model proposed in figure 7.

A second avenue should seek to explore the nature of and the reasons for the extreme levels of fidgeting we find. Further research needs to tease out the internal, automatic motivators of this 
behaviour and the ecological factors that trigger fidgeting. It also needs to confirm whether the phone is actually the most common target object of fidgeting, as in our observations, and why this is the case. From a methodological perspective, there also needs to be an investigation on how to best study this phenomenon using automated and logging methods, as fidgeting looks like normal usage on current logs, but in vivo methods alone will not be able to provide sufficiently large and reliable numbers. And finally, as cognitive attractor strength is a combination of high salience, reward value, and (low) cost of completion, research on design for less phone fidgeting could explore enabling users to increase the ergonomic cost of interaction with the phone when they want to not self-disrupt.

A third avenue to be developed would be to connect the findings about high-frequency, userinitiated smartphone interactions with the recently emerging literature on the role of dopamine for smartphone use. Several researchers and industry professionals suggest that smartphones and social media leverage the dopamine response, which gets users addicted to a feedback loop (Haynes, 2018; Parkin, 2018; Weinschenk, 2012), but there is no solid confirmation of this relationship yet (Ley, 2017).

Finally, seeing that participants struggle with some of the habits they have developed, a fourth avenue for further research should look into how these habits form over time and how they can be better aligned with the preferences users report. We propose that internet literacy should be understood in a more nuanced way: While most educational and research programs to date focus on understanding and training audiences on what could be called content literacy, i.e. how to not get one's credit card data stolen, or worse, groomed, research should also focus on attention literacy, which will enable users to make more informed and conscious choices on when and how to use these undoubtedly powerful tools, and when not to.

\section{Limitations}

We have employed a mixed-methods approach to triangulate our findings, but this study is ultimately based on data from 37 participants. While quantitative approaches using device and application logs would not have been able to obtain some of the findings of our study, they produce more reliable data on usage patterns, which is needed to consolidate the evidence we have found. This, in combination with the mixture of conforming and contrasting results from previous studies substantiates the case for replication of smartphone use studies that has been argued in the mobile HCI community in recent years (Banovic, 2016; Church et al., 2015; Wilson \& Mackay, 2011). It is important to bear in mind that, while the differences in results may be due to the different study populations, there also might be a gradual shift in usage that may occur over the years, which is then reflected in differences between the 'snapshots' that individual studies take.

From a methodological point of view, while SEBE allows a much more detailed look into the subjective experiences of users, we have not assessed which specific notifications participants had activated or disactivated, and the influence of changing the devices' notification settings on perceived disruptiveness in this paper. While this would be highly interesting, it is very difficult to reliably record in naturally occurring contexts as most people change these settings situationally (e.g. while waiting for a call); a more streamlined approach using SEBE in a slightly more controlled environment may be more suited to investigate these questions. Nevertheless, the key point remains that participants feel the phones disrupt them, when they actually self-disrupt in the majority of cases, whether different types of notifications are turned on or off. 


\section{Conclusion}

In this paper, we have investigated the disruptiveness of smartphones with a situated firstperson technique. We have found that participants report ambivalent, but very intimate relationships with their phones. While researchers and participants are in agreement that smartphones are the most powerful everyday tool we have, it has also become clear that they are a source of distraction and social pressure. We have further shown that smartphone use is largely habitualised with frequencies of user interactions being invariant across different locations and contexts. Moreover, it has emerged that $89 \%$ of smartphone interactions in our sample are initiated by users, rather than by devices. Overall, our findings purport that the perceived disruptiveness of smartphones is not mainly driven by external notifications, as commonly argued in the literature and by users, but by an urge of the user to interact with their phone that seems to occur in an almost automatic manner, just as a smoker would light a cigarette; and also by the process of being "caught in the loop" of chaining various activities in an unplanned fashion. In other words, it seems that the affordance of the phone for interaction is so strong that a lot of such interactions emerge spontaneously without the need for a pulling notification by the phone, nor a clear and strong intention of the user.

The notion of "disruption" carries the implicit idea that the cause of disruption is external to the person. What appears from our data is that disruption can have internal causes (like coughing disrupts talking), that smartphone use embodies a habitual drive to check the device which becomes an internal cause of disruption, that users are not fully aware of the frequency of this drive until they watch their own recordings, and that they are not happy with what they realise. We therefore suggest that we cannot rely on designing device-centred, high-tech solutions to every problem technology causes, but need to turn towards understanding and shaping embodied competences and habitualised behaviours of users. In the case of smartphones, it appears that users may need to re-learn how to engage with their devices healthily. An exciting avenue for design is to support users in acquiring better attention literacy and reflecting on their use of time, which would be beneficial for a more discerning use of screens, and possibly for their life in general. 


\section{References}

Adamczyk, P. D., \& Bailey, B. P. (2004). If not now when?: the effects of interruption at different moments within task execution. Proceedings of the SIGCHI Conference on Human Factors in Computing Systems. https://doi.org/10.1145/985692.985727

Anderson, C., Heinisch, J. S., Ohly, S., David, K., \& Pejovic, V. (2019). The impact of private and work-related smartphone usage on interruptibility. In UbiComp/ISWC 2019- Adjunct Proceedings of the 2019 ACM International Joint Conference on Pervasive and Ubiquitous Computing and Proceedings of the 2019 ACM International Symposium on Wearable Computers. https://doi.org/10.1145/3341162.3344845

Arnold, M. (2003). On the phenomenology of technology: The "Janus-faces" of mobile phones. Information and Organization. https://doi.org/10.1016/S1471-7727(03)00013-7

Baek, Y. M., Cho, Y., \& Kim, H. (2014). Attachment Style and its Influence on the Activities, Motives, and Consequences of SNS Use. Journal of Broadcasting and Electronic Media, 58(4), 522-541. https://doi.org/10.1080/08838151.2014.966362

Banovic, N. (2016). To Replicate or Not to Replicate? GetMobile: Mobile Computing and Communications, 19(4), 23-27. https://doi.org/10.1145/2904337.2904346

Banovic, N., Brant, C., Mankoff, J., \& Dey, A. K. (2014). ProactiveTasks: The short of mobile device use sessions. In MobileHCI 2014 - Proceedings of the 16th ACM International Conference on Human-Computer Interaction with Mobile Devices and Services. https://doi.org/10.1145/2628363.2628380

Baym, N. K., \& Boyd, D. (2012). Socially Mediated Publicness: An Introduction. Journal of Broadcasting and Electronic Media, 56(3), 320-329. https://doi.org/10.1080/08838151.2012.705200

Beja, I., Lanir, J., \& Kuflik, T. (2015). Examining Factors Influencing the Disruptiveness of Notifications in a Mobile Museum Context. Human-Computer Interaction. https://doi.org/10.1080/07370024.2015.1005093

Bertel, T. F. (2013). "It's like I trust it so much that I don't really check where it is I'm going before I leave": Informational uses of smartphones among Danish youth. Mobile Media and Communication. https://doi.org/10.1177/2050157913495386

Boyd, D. M. (2007). Why youth (heart) Social network sites: the role of networked publics in teenage social life. MacArthur Foundation Series on Digital Learning - Youth, Identity, and Digital Media. https://doi.org/10.1162/dmal.9780262524834.119

Bradner, E., Kellogg, W. A., \& Erickson, T. (1999). The Adoption and Use of 'Babble': A Field Study of Chat in the Workplace. In ECSCW' 99. https://doi.org/10.1007/978-94011-4441-4_8

Brown, B., McGregor, M., \& Laurier, E. (2013). iPhone in Vivo: Video Analysis of Mobile Device Use. In Proceedings of the SIGCHI Conference on Human Factors in Computing Systems (pp. 1031-1040). New York, NY, USA: ACM. https://doi.org/10.1145/2470654.2466132

Brown, B., McGregor, M., \& McMillan, D. (2014). 100 days of iPhone use: Understanding the details of mobile device use. In MobileHCI 2014 - Proceedings of the 16th ACM International Conference on Human-Computer Interaction with Mobile Devices and Services. https://doi.org/10.1145/2628363.2628377

Brown, B., McGregor, M., \& McMillan, D. (2015). Searchable Objects: Search in Everyday Conversation. In Proceedings of the 18th ACM Conference on Computer Supported Cooperative Work \&\#38; Social Computing (pp. 508-517). New York, NY, USA: ACM. https://doi.org/10.1145/2675133.2675206

Chiu, S. I. (2014). The relationship between life stress and smartphone addiction on taiwanese university student: A mediation model of learning self-Efficacy and social 
self-Efficacy. Computers in Human Behavior. https://doi.org/10.1016/j.chb.2014.01.024 Church, K., Ferreira, D., Banovic, N., \& Lyons, K. (2015). Understanding the Challenges of Mobile Phone Usage Data. In Proceedings of the 17th International Conference on Human-Computer Interaction with Mobile Devices and Services (pp. 504-514). New York, NY, USA: Association for Computing Machinery. https://doi.org/10.1145/2785830.2785891

Cudo, A., Francuz, P., Augustynowicz, P., \& Stróżak, P. (2018). The Effects of Arousal and Approach Motivated Positive Affect on Cognitive Control. An ERP Study. Frontiers in Human Neuroscience. https://doi.org/10.3389/fnhum.2018.00320

De Russis, L., \& Monge Roffarello, A. (2017). On the Benefit of Adding User Preferences to Notification Delivery. In CHI EA '17 Proceedings of the 2017 CHI Conference Extended Abstracts on Human Factors in Computing Systems (pp. 1561-1568). https://doi.org/10.1145/3027063.3053160

Do, T. M. T., Blom, J., \& Gatica-Perez, D. (2011). Smartphone usage in the wild: A largescale analysis of applications and context. In ICMI'11 - Proceedings of the 2011 ACM International Conference on Multimodal Interaction. https://doi.org/10.1145/2070481.2070550

Everri, M., Heitmayer, M., Yamin-Slotkus, P., \& Lahlou, S. (2020). Ethical challenges of using video for qualitative research and ethnography. In A.-K. Koistinen, T. Lähdesmäki, \& V. Čeginskas (Eds.), Ethnography with a Twist. Methodological and Ethical Challenges and Solutions in Contemporary Research. Milton Park: Routledge.

Exler, A., Braith, M., Schankin, A., \& Beigl, M. (2016). Preliminary Investigations About Interruptibility of Smartphone Users at Specific Place Types. In Proceedings of the 2016 ACM International Joint Conference on Pervasive and Ubiquitous Computing: Adjunct (pp. 1590-1595). New York, NY, USA: ACM. https://doi.org/10.1145/2968219.2968554

Exler, A., Dinse, C., Günes, Z., Hammoud, N., Mattes, S., \& Beigl, M. (2017). Investigating the Perceptibility Different Notification Types on Smartphones Depending on the Smartphone Position. In Proceedings of the 2017 ACM International Joint Conference on Pervasive and Ubiquitous Computing and Proceedings of the 2017 ACM International Symposium on Wearable Computers (pp. 970-976). New York, NY, USA: ACM. https://doi.org/10.1145/3123024.3124560

Fisher, R., \& Simmons, R. (2011). Smartphone interruptibility using density-weighted uncertainty sampling with reinforcement learning. In Proceedings - 10th International Conference on Machine Learning and Applications, ICMLA 2011. https://doi.org/10.1109/ICMLA.2011.128

Fitz, N., Kushlev, K., Jagannathan, R., Lewis, T., \& Paliwal, D. (2019). Batching smartphone notifications can improve well-being. Computers in Human Behavior, 1-23. https://doi.org/10.1016/j.chb.2019.07.016

Frissen, V. A. J. (2000). ICTs in the Rush Hour of Life. The Information Society, 16(1), 6575. https://doi.org/10.1080/019722400128338

Glăveanu, V. P., \& Lahlou, S. (2012). Through the Creator's Eyes: Using the Subjective Camera to Study Craft Creativity. Creativity Research Journal, 24(2-3), 152-162. https://doi.org/10.1080/10400419.2012.677293

Hamermesh, D. S., \& Jungmin, L. (2007). Stressed out on four continents: Time crunch or yuppie kvetch? Review of Economics and Statistics. https://doi.org/10.1162/rest.89.2.374

Hargittai, E., \& Hsieh, Y. li P. (2010). Predictors and consequences of differentiated practices on social network sites. Information Communication and Society, 13(4), 515-536. https://doi.org/10.1080/13691181003639866 
Hargittai, E., \& Walejko, G. (2008). The participation divide: Content creation and sharing in the digital age. Information Communication and Society, 11(2), 239-256.

https://doi.org/10.1080/13691180801946150

Haynes, T. (2018). Dopamine, Smartphones \& You: A battle for your time. Retrieved September 10, 2019, from http://sitn.hms.harvard.edu/flash/2018/dopaminesmartphones-battle-time/

Höge, T. (2009). When work strain transcends psychological boundaries: An inquiry into the relationship between time pressure, irritation, work-family conflict and psychosomatic complaints. Stress and Health. https://doi.org/10.1002/smi.1226

Horvitz, E., Koch, P., \& Apacible, J. (2004). BusyBody: creating and fielding personalized models of the cost of interruption. Proceedings of the 2004 ACM Conference on Computer Supported Cooperative Work - CSCW' 04. https://doi.org/10.1145/1031607.1031690

Humphreys, L. (2012). Connecting, Coordinating, Cataloguing: Communicative Practices on Mobile Social Networks. Journal of Broadcasting and Electronic Media, 56(4), 494510. https://doi.org/10.1080/08838151.2012.732144

Iqbal, S. T., \& Bailey, B. P. (2007). Understanding and Developing Models for Detecting and Differentiating Breakpoints During Interactive Tasks. In Proceedings of the SIGCHI Conference on Human Factors in Computing Systems (pp. 697-706). New York, NY, USA: ACM. https://doi.org/10.1145/1240624.1240732

Iqbal, S. T., \& Bailey, B. P. (2008). Effects of Intelligent Notification Management on Users and Their Tasks. In Proceedings of the SIGCHI Conference on Human Factors in Computing Systems (pp. 93-102). New York, NY, USA: ACM. https://doi.org/10.1145/1357054.1357070

Iqbal, S. T., \& Horvitz, E. (2010). Notifications and awareness: A field study of alert usage and preferences. Proceedings of the 2010 ACM Conference on Computer Supported Cooperative Work - CSCW'10, 27-30. Retrieved from http://portal.acm.org/citation.cfm?doid=1718918.1718926\%5Cnhttp://dl.acm.org/citatio n.cfm?id=1718918.1718926

Ishii, K. (2006). Implications of mobility: The uses of personal communication media in everyday life. Journal of Communication. https://doi.org/10.1111/j.14602466.2006.00023.x

Jones, L., McClelland, J., Thongsouksanoumane, P., \& Girouard, A. (2017). Ambient Notifications with Shape Changing Circuits in Peripheral Locations. In Proceedings of the 2017 ACM International Conference on Interactive Surfaces and Spaces (pp. 405408). New York, NY, USA: ACM. https://doi.org/10.1145/3132272.3132291

Kobayashi, K., \& Yamada, S. (2013). Shape changing device for notification. In UIST '13 Adjunct Proceedings of the adjunct publication of the 26th annual ACM symposium on User interface software and technology (pp. 71-72). https://doi.org/10.1145/2508468.2514715

Kushlev, K., Proulx, J., \& Dunn, E. W. (2016). "Silence Your Phones": Smartphone Notifications Increase Inattention and Hyperactivity Symptoms. In Proceedings of the 2016 CHI Conference on Human Factors in Computing Systems (pp. 1011-1020). New York, NY, USA: ACM. https://doi.org/10.1145/2858036.2858359

Lahlou, S. (2007). Human activity modeling for systems design: a trans-disciplinary and empirical approach. Engineering Psychology and Cognitive Ergonomics, 4562(section 2), 512-521.

Lahlou, S. (2011). How can we capture the subject's perspective? An evidence-based approach for the social scientist. Social Science Information, 50(3-4), 607-655. https://doi.org/10.1177/0539018411411033 
Lahlou, S. (2018). Installation theory: The societal construction and regulation of behaviour. Installation Theory: The Societal Construction and Regulation of Behaviour. https://doi.org/10.1017/9781316480922

Lahlou, S., Le Bellu, S., \& Boesen-Mariani, S. (2015). Subjective Evidence Based Ethnography: Method and Applications. Integrative Psychological and Behavioral Science, 49(2), 216-238. https://doi.org/10.1007/s12124-014-9288-9

Lenhart, A. (2012). Teens, Smartphones \& Texting. Pew Research Center.

Ley, D. (2017). No, Dopamine is Not Addictive. Retrieved September 10, 2019, from https://www.psychologytoday.com/us/blog/women-who-stray/201701/no-dopamine-isnot-addictive

Licoppe, C., \& Figeac, J. (2013). Patterns of Gaze Switching in the "Naturally-Occurring" Uses of Smartphones in Urban Mobile Settings. Paris: TELECOM ParisTech.

Lopez-Tovar, H., Charalambous, A., \& Dowell, J. (2015). Managing Smartphone Interruptions Through Adaptive Modes and Modulation of Notifications. In Proceedings of the 20th International Conference on Intelligent User Interfaces (pp. 296-299). New York, NY, USA: ACM. https://doi.org/10.1145/2678025.2701390

Mayer, S., Lischke, L., Woźniak, P., \& Henze, N. (2018). Evaluating the Disruptiveness of Mobile Interactions: A Mixed-Method Approach. In Proceedings of the $2018 \mathrm{CHI}$ Conference on Human Factors in Computing Systems (pp. 406:1--406:14). New York, NY, USA: ACM. https://doi.org/10.1145/3173574.3173980

Mayring, P. (2000). Qualitative Content Analysis. FQS - Forum Qualitative Social Research. Mayring, P. (2015). Qualitative Content Analysis: Theoretical Background and Procedures. https://doi.org/10.1007/978-94-017-9181-6_13

McFarlane, D. C. (1999). Coordinating the interruption of people in human-computer interaction. Human-Computer Interaction, INTERACT'99: IFIP TC. 13 International Conference on Human-Computer Interaction, 30th August-3rd September 1999, Edinburgh, UK.

McMillan, D., Brown, B., Lampinen, A., McGregor, M., Hoggan, E., \& Pizza, S. (2017). Situating Wearables. Proceedings of the 2017 CHI Conference on Human Factors in Computing Systems - CHI '17, 3582-3594. https://doi.org/10.1145/3025453.3025993

Mehrotra, A., \& Musolesi, M. (2017). Intelligent Notification Systems: A Survey of the State of the Art and Research Challenges. CoRR, abs/1711.1. Retrieved from http://arxiv.org/abs/1711.10171

Mehrotra, A., Pejovic, V., Vermeulen, J., Hendley, R., \& Musolesi, M. (2016). My Phone and Me: Understanding People's Receptivity to Mobile Notifications. In Proceedings of the 2016 CHI Conference on Human Factors in Computing Systems (pp. 1021-1032). New York, NY, USA: ACM. https://doi.org/10.1145/2858036.2858566

Milewski, A. E. (2006). Interruption management and telephone call screening. International Journal of Human-Computer Interaction, 20(1), 19-33. https://doi.org/10.1207/s15327590ijhc2001_3

Morrison, A., Xiong, X., Higgs, M., Bell, M., \& Chalmers, M. (2018). A large-scale study of iPhone app launch behaviour. In Conference on Human Factors in Computing Systems Proceedings. https://doi.org/10.1145/3173574.3173918

Oh, H., Jalali, L., \& Jain, R. (2015). An intelligent notification system using context from real-time personal activity monitoring. In Proceedings - IEEE International Conference on Multimedia and Expo. https://doi.org/10.1109/ICME.2015.7177508

Okoshi, T., Nozaki, H., Nakazawa, J., Tokuda, H., Ramos, J., \& Dey, A. K. (2016). Towards attention-aware adaptive notification on smart phones. Pervasive and Mobile Computing. https://doi.org/10.1016/j.pmcj.2015.10.004

Okoshi, T., Tokuda, H., \& Nakazawa, J. (2016). Interruptibility research: Opportunities for 
future flourishment. In UbiComp 2016 Adjunct - Proceedings of the 2016 ACM International Joint Conference on Pervasive and Ubiquitous Computing. https://doi.org/10.1145/2968219.2968543

Oulasvirta, A., Tamminen, S., Roto, V., \& Kuorelahti, J. (2005). Interaction in 4-second bursts: The fragmented nature of attentional resources in mobile HCI. CHI 2005: Technology, Safety, Community: Conference Proceedings - Conference on Human Factors in Computing Systems, 919-928.

Parkin, S. (2018). Has dopamine got us hooked on tech?|Technology | The Guardian. Retrieved September 10, 2019, from https://www.theguardian.com/technology/2018/mar/04/has-dopamine-got-us-hookedon-tech-facebook-apps-addiction

Pejovic, V., \& Musolesi, M. (2014). InterruptMe: Designing intelligent prompting mechanisms for pervasive applications. In UbiComp 2014 - Proceedings of the 2014 ACM International Joint Conference on Pervasive and Ubiquitous Computing. https://doi.org/10.1145/2632048.2632062

Pielot, M., de Oliveira, R., Kwak, H., \& Oliver, N. (2014). Didn'T You See My Message?: Predicting Attentiveness to Mobile Instant Messages. In Proceedings of the SIGCHI Conference on Human Factors in Computing Systems (pp. 3319-3328). New York, NY, USA: ACM. https://doi.org/10.1145/2556288.2556973

Pizza, S., Brown, B., McMillan, D., \& Lampinen, A. (2016). Smartwatch in Vivo. In Proceedings of the 2016 CHI Conference on Human Factors in Computing Systems (pp. 5456-5469). New York, NY, USA: ACM. https://doi.org/10.1145/2858036.2858522

Rasmussen, M. K., Troiano, G. M., Petersen, M. G., Simonsen, J. G., \& Hornbæk, K. (2016). Sketching Shape-changing Interfaces: Exploring Vocabulary, Metaphors Use, and Affordances. In Proceedings of the 2016 CHI Conference on Human Factors in Computing Systems (pp. 2740-2751). New York, NY, USA: ACM. https://doi.org/10.1145/2858036.2858183

Reeves, B., Roy, S., Gorman, B., \& Morley, T. (2008). A marketplace for attention: Responses to a synthetic currency used tosignal information importance in e-mail. First Monday.

Roxburgh, S. (2004). "There just aren't enough hours in the day": The mental health consequences of time pressure. Journal of Health and Social Behavior. https://doi.org/10.1177/002214650404500201

Sbarra, D. A., Briskin, J. L., \& Slatcher, R. B. (2019). Smartphones and Close Relationships: The Case for an Evolutionary Mismatch. Perspectives on Psychological Science. https://doi.org/10.1177/1745691619826535

Schreier, M. (2014). The SAGE Handbook of Qualitative Data Analysis Qualitative Content Analysis. The SAGE Handbook of Qualitative Data Analysis. https://doi.org/10.4135/9781446282243

Schroer, M. (2014). Visual Culture and the Fight for Visibility. Journal for the Theory of Social Behaviour. https://doi.org/10.1111/jtsb.12038

Schulze, F., \& Groh, G. (2014). Studying how character of conversation affects personal receptivity to mobile notifications. In CHI EA '14 CHI '14 Extended Abstracts on Human Factors in Computing Systems (pp. 1729-1734). https://doi.org/10.1145/2559206.2581320

Schulze, F., \& Groh, G. (2016). Conversational Context Helps Improve Mobile Notification Management. In Proceedings of the 18th International Conference on Human-Computer Interaction with Mobile Devices and Services (pp. 518-528). New York, NY, USA: ACM. https://doi.org/10.1145/2935334.2935347

Smith, J., Lavygina, A., Ma, J., Russo, A., \& Dulay, N. (2014). Learning to Recognise 
Disruptive Smartphone Notifications. In Proceedings of the 16th International Conference on Human-computer Interaction with Mobile Devices \&\#38; Services (pp. 121-124). New York, NY, USA: ACM. https://doi.org/10.1145/2628363.2628404

Smith, J., Lavygina, A., Russo, A., \& Dulay, N. (2014). When did your smartphone bother you last? In UbiComp '14 Adjunct Proceedings of the 2014 ACM International Joint Conference on Pervasive and Ubiquitous Computing: Adjunct Publication (pp. 409414). https://doi.org/10.1145/2638728.2641701

Tams, S., Thatcher, J., Grover, V., \& Pak, R. (2015). Selective attention as a protagonist in contemporary workplace stress: implications for the interruption age. Anxiety, Stress and Coping. https://doi.org/10.1080/10615806.2015.1011141

Tulving, E. (2002). Episodic Memory: From Mind to Brain. Annual Review of Psychology, (53), 1-25.

Turkle, S. (2015). Reclaiming conversation : the power of talk in a digital age. New York: Penguin Press.

Van Berkel, N., Luo, C., Anagnostopoulos, T., Ferreira, D., Goncalves, J., Hosio, S., \& Kostakos, V. (2016). A systematic assessment of smartphone usage gaps. In Conference on Human Factors in Computing Systems - Proceedings. https://doi.org/10.1145/2858036.2858348

Visuri, A., Sarsenbayeva, Z., Van Berkel, N., Goncalves, J., Rawassizadeh, R., Kostakos, V., \& Ferreira, D. (2017). Quantifying sources and types of smartwatch usage sessions. Conference on Human Factors in Computing Systems - Proceedings, 2017-May, 35693581. https://doi.org/10.1145/3025453.3025817

Walsh, S. P., White, K. M., \& Young, R. M. (2008). Over-connected? A qualitative exploration of the relationship between Australian youth and their mobile phones. Journal of Adolescence. https://doi.org/10.1016/j.adolescence.2007.04.004

Weber, D., Voit, A., Exler, A., Schröder, S., Böhmer, M., \& Okoshi, T. (2017). Intelligent Notification and Attention Management on Mobile Devices. In Proceedings of the 16th International Conference on Mobile and Ubiquitous Multimedia (pp. 561-565). New York, NY, USA: ACM. https://doi.org/10.1145/3152832.3152840

Weinschenk, S. (2012). Why We're All Addicted to Texts, Twitter and Google. Retrieved September 10, 2019, from https://www.psychologytoday.com/us/blog/brainwise/201209/why-were-all-addicted-texts-twitter-and-google

Westermann, T., Möller, S., \& Wechsung, I. (2015). Assessing the Relationship Between Technical Affinity, Stress and Notifications on Smartphones. In Proceedings of the 17th International Conference on Human-Computer Interaction with Mobile Devices and Services Adjunct (pp. 652-659). New York, NY, USA: ACM. https://doi.org/10.1145/2786567.2793684

Westermann, T., Wechsung, I., \& Möller, S. (2016). Smartphone Notifications in Context: A Case Study on Receptivity by the Example of an Advertising Service. In Proceedings of the 2016 CHI Conference Extended Abstracts on Human Factors in Computing Systems (pp. 2355-2361). New York, NY, USA: ACM.

https://doi.org/10.1145/2851581.2892383

Wilson, M. L., \& Mackay, W. (2011). RepliCHI - CHI should be replicating and validating results more: Discuss. Conference on Human Factors in Computing Systems Proceedings, 463-466. https://doi.org/10.1145/1979742.1979491

Yan, T., Chu, D., Ganesan, D., Kansal, A., \& Liu, J. (2012). Fast app launching for mobile devices using predictive user context. MobiSys'12 - Proceedings of the 10th International Conference on Mobile Systems, Applications, and Services, 113-126. https://doi.org/10.1145/2307636.2307648

Yeykelis, L., Cummings, J. J., \& Reeves, B. (2014). Multitasking on a Single Device: 
Arousal and the Frequency, Anticipation, and Prediction of Switching Between Media Content on a Computer. Journal of Communication. https://doi.org/10.1111/jcom.12070 Yeykelis, L., Cummings, J. J., \& Reeves, B. (2018). The Fragmentation of Work,

Entertainment, E-Mail, and News on a Personal Computer: Motivational Predictors of Switching Between Media Content. Media Psychology. https://doi.org/10.1080/15213269.2017.1406805

Yuan, F., Gao, X., \& Lindqvist, J. (2017). How Busy Are You?: Predicting the Interruptibility Intensity of Mobile Users. In Proceedings of the 2017 CHI Conference on Human Factors in Computing Systems (pp. 5346-5360). New York, NY, USA: ACM. https://doi.org/10.1145/3025453.3025946 